\title{
A Opção pelo Teatro em Comunidades: ALTERNATIVAS DE PESQUISA
}

\author{
Márcia Pompeo Nogueira ${ }^{1}$
}

O significado do Teatro em Comunidade ficou claro para mim quando estreamos o espetáculo “A Outra História do Boi”, em Ratones, em 1995. Era o terceiro espetáculo feito pelas crianças e jovens desta comunidade, desde que iniciamos o projeto de extensão² em 1991. Na apresentação deste espetáculo saímos da escola - local onde aconteciam as oficinas - e apresentamos no centro comunitário da igreja local. O espaço estava lotado de pessoas da comunidade que, na grande maioria, nunca tinha assistido a uma peça teatral.

O tema da montagem havia nascido de uma investigação com os moradores dessa comunidade motivada por uma curiosidade: por que uma comunidade do interior da Ilha de Santa Catarina, mais preservada em relação ao turismo do que outras comunidades de Florianópolis, não possuía um grupo de Boi de Mamão, tão popular nas outras comunidades? Entrevistando os moradores, descobrimos que a brincadeira era viva na comunidade, mas parou de ser praticada há trinta anos. Em função desta resposta, Reonaldo Manoel Gonçalves (Nado), um dos integrantes de nossa equipe, coordenou um processo de resgate do Boi de Mamão, em Ratones, identificando os antigos praticantes do Boi e incluindo as crianças e os jovens do grupo de teatro na revitalização da brincadeira.

Durante as entrevistas, uma pessoa nos deu uma informação curiosa. Disse ter havido um assassinato da pessoa que dançava no miolo do boi, durante uma apresentação e que depois disso nunca mais se dançou o Boi de Mamão em Ratones. Não pudemos confirmar esse depoimento com outros moradores, mas ele nos motivou na criação do espetáculo "A Outra História do Boi”. Esse dado, verídico ou não, simboliza a morte das tradições culturais em Ratones. O processo

${ }^{1}$ Márcia Pompeo Nogueira é professora do CEART/UDESC, doutora em Drama pela Universidade de Exeter, Inglaterra.

2Projeto "Teatro com Crianças e Adolescentes" do Centro de Artes da UDESC. 
de montagem foi feito em torno dessa informação, envolvendo também, na construção dos personagens, conteúdos e formas pesquisados pelos atores junto a pessoas da comunidade. Por outro lado, o processo criativo envolveu a pesquisa sobre teatro de sombras que, somada à prática de jogos teatrais, já incorporada na representação do grupo, representou um passo a mais na sua expressão estética.

Não sei ao certo se foi pela vinculação com as tradições culturais da comunidade, se pelo envolvimento da comunidade com a pesquisa do Boi de Mamão, que divulgou o trabalho teatral que lá acontecia, se pelo nosso histórico junto com a comunidade, já que desenvolvíamos o trabalho teatral há vários anos ou mesmo se foi pela qualidade estética do grupo que - apesar de ser bem diferente de uma estética de um teatro profissional - já tinha um domínio considerável dessa linguagem artística. O certo é que o espetáculo atraiu um número enorme de moradores que participou tão ativamente da apresentação que me fez optar definitivamente por este tipo de teatro. Lembrome dos comentários feitos em voz alta sobre o que acontecia em cena, das risadas, do burburinho, dos aplausos e da felicidade dos integrantes do grupo após a apresentação. Era um teatro vivo!

Passei então a nomear meu trabalho de Teatro na Comunidade. Logo um colega me questionou. Comunidade? Como falar em comunidade na contemporaneidade, justamente no momento em que diversos teóricos questionam sua existência?

\section{O Conceito de Comunidade}

O conceito de comunidade, debatido por Zygmunt Bauman, apóiase no conceito de Ferdinando Tönnies de Gemeinschaft - um espaço de "entendimento compartilhado por todos os seus membros" (Bauman, 2003,p.15), onde o entendimento comum flui naturalmente - para dizer que essa comunidade não existe.

Refletindo sobre este conceito, Bauman esclarece que não se trata de um consenso adquirido no debate. Trata-se de um tipo de entendimento que precede todos os acordos e desacordos. Não é um pondo de chegada, mas um ponto de partida (ibidem, p.15). A comunidade que habitamos é bem diferente desse paraíso perdido.

A comunidade realmente existente se parece com uma fortaleza sitiada, continuamente bombardeada por inimigos (muitas vezes invisiveis) de fora e freqüentemente assolada pela discórdia 
interna; trincheiras e baluartes são os lugares onde os que procuram o aconchego, a simplicidade e a tranqüilidade comunitárias terão que passar a maior parte de seu tempo. (ibidem, p.19)

Já no conceito de comunidade proposto por Anthony Cohen, os embates dentro e fora da comunidade fazem parte de uma construção de sentido. Uma instância de negociação de significados que se situa num espaço intermediário entre a família e a sociedade:

[Comunidade] É a entidade à qual as pessoas pertencem, maior que as relações de parentesco, mas mais imediata do que a abstração a que chamamos de "sociedade". É a arena onde as pessoas adquirem suas experiências mais fundamentais e substanciais da vida social, fora dos limites do lar. (Cohen: 1998, p. 15)

Para Cohen, a comunidade não significa a mesma coisa para todas as pessoas. Ela é um símbolo de algo comum. As pessoas podem compartilhar símbolos sem compartilhar significados.

Por sua natureza, os símbolospermitem interpretação o oferecem possibilidades de manobras interpretativas para aqueles que os usam. Os símbolos são frequentemente definidos como coisas que se colocam 'no lugar' de outras. Mas eles não representam essas outras coisas sem ambiguidades. (...) Eles podem portanto prover um meio através do qual indivíduos podem experimentar e expressar seus vínculos com uma sociedade sem comprometer suas individualidades. (ibidem, p. 18)

Como exemplo ele analisa este símbolo:

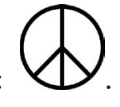
associam a este símbolo podem ter posições diferentes sobre muitos dos significados atrelados a ele no que diz respeito, por exemplo, a sua atitude em relação à OTAN ou ao bloco soviético, à importância do cristianismo, pacifismo, socialismo, apoio ao desarmamento nuclear. (ibidem, p. 18) Portanto, pessoas com visões opostas podem aderir ao mesmo símbolo por diferentes razões. Podem também mudar seu entendimento sobre essa opção a partir do debate no interior dessa comunidade.

Comunidade e tudo o que existe nela, conceitualmente $e$ materialmente, tem uma dimensão simbólica, e, mais profundamente, esta dimensão não existe enquanto um consenso de sentimento. Em vez disso, existe como algo para as pessoas 'pensarem'. Os símbolos 
são construções mentais: permitem às pessoas fazerem sentido. Dessa forma, também possibilitam a elas os meios de expressão do significado particular que a comunidade tem para eles. (ibidem, p. 19)

Mesmo entendendo que Bauman contribui para a reflexão sobre o significado da comunidade na contemporaneidade, é o conceito proposto por Cohen que mais contribui para o nosso entendimento sobre teatro na comunidade.

A afirmação de um teatro voltado para comunidades específicas pode ser aprofundada pelo entendimento de que a comunidade, pelo menos enquanto um símbolo comum, existe e que o teatro pode contribuir para a necessária e permanente construção do sentido da comunidade.

Reforçando meu comprometimento sobre este tipo de teatro, entrei em contato com o debate internacional nesta área. De um modo geral, pude aprofundar meu entendimento sobre este tipo de teatro e sobre o significado da prática desenvolvida em Ratones. Por outro lado, pude identificar que o preconceito ao teatro em comunidades também existe fora do Brasil, como bem pontua Eugene van Erven:

Não são somente os participantes considerados periféricos. Teatro em comunidade como uma forma artística também o é (2001, p. 2).

\section{Nomenclatura e significado}

De um modo geral o teatro em comunidade existe em todos os continentes do planeta, mas são vários os entendimentos sobre o seu significado e são vários também os termos utilizados para nomeá-lo. Baz Kershaw propõe a seguinte definição de Community Theatre (Teatro na Comunidade):

Sempre que o ponto de partida [de uma prática teatral] for a natureza de seu público e sua comunidade. Que a estética de suas performances for talhada pela cultura da comunidade, de sua audiência. Neste sentido estas práticas podem ser categorizadas enquanto Community Theatre (Teatro na Comunidade). (Kershaw: 1992, p. 5)

Para Kershaw, toda comunidade é parecida no que diz respeito às diferenças internas que abriga e ao papel de mediação que assume entre o indivíduo e a sociedade. Ele cita dois tipos de comunidade: 


\section{Urdimento}

'Comunidade de local' é criada por uma rede de relacionamentos formados por interações face a face, numa área delimitada geograficamente.

'Comunidade de interesse', como a frase sugere, são formadas por uma rede de associações que são predominantemente caracterizadas por seu comprometimento em relação a um interesse comum. Quer dizer que estas comunidades podem não estar delimitadas por uma área geográfica particular. Quer dizer também que comunidades de interesse tendem a ser explícitas ideologicamente, de forma a que mesmo que seus membros venham de áreas geográficas diferentes, eles podem de forma relativamente fácil reconhecer sua identidade comum. (ibidem, p. 31)

No primeiro sentido, acredita-se que pessoas que vivem e/ou trabalham numa mesma região possuem determinadas vivências e problemas comuns, enquanto o segundo indica que algumas pessoas comungam de idéias, se identificam por um olhar preconceituoso com que são vistas, ou sofrem uma mesma exclusão, como por exemplo: mulheres, homossexuais, negros, meninos de rua, domésticas, entre outros.

Eugene van Erven utiliza a mesma nomenclatura e sua definição é semelhante à de Kershaw:

Community Theatre (Teatro na Comunidade) é um fenômeno mundial que se manifesta de diferentes formas, produzindo uma ampla gama de estilos de representação. Elas se unem, eu penso, por sua ênfase em histórias pessoais e/ou locais (no lugar de peças prontas) que são trabalhadas através de improvisação e ganham coletivamente uma forma teatral sob a direção de um artista profissional - que pode ou não estar ativo em outros tipos de teatro profissional - ou de um artista amador que reside com o grupo que, por falta de um termo melhor, pode talvez ser chamado de "periférico". (Erven, 2001, p. 2)

Jan Cohen $\mathrm{Cruz}^{3}$, da Universidade de Nova York, também se refere a uma prática teatral criada a partir de interações com comunidades específicas, mas o termo que ela utiliza é Community-based performance (Teatro baseado na comunidade):

Uma produção de community-based performance é geralmente uma resposta a um assunto ou circunstância coletivamente significativos. É uma colaboração entre um artista ou grupo de artistas

\footnotetext{
${ }^{3} J a n$ Cohen Cruz é autora dos livros Local Acts: Community Based Performance in the United States. New Jersey: Rutgers University Press, 2005; Radical Street Performance: an international anthology. Londres: Routledge, 1998; Cohen-Cruz, Jan; Shutzman. Playing Boal: Theatre, Therapy, Activism. Londres: Routledge, $1994 \mathrm{e}$ A Boal Companion: Dialogues on Theatre and Cultural Politics. Londres: Routledge, 2006.
} 


\section{Urdimento}

${ }^{4}$ Helen Nicholson é do Departamento de Drama e Teatro da Royal Holloway, Universidade de Londres.
${ }^{5}$ Professor associado do Departamento de Música e Artes da Performance, da Universidade de Nova York. e uma "comunidade" na qual a última é a fonte principal do texto, possivelmente também dos atores, e definitivamente de grande parte do público. Ou seja, a base da community-based performance não é o artista individualmente, mas sim uma "comunidade" constituída por meio de uma identidade primária compartilhada, baseada em local, etnia, classe, raça, preferência sexual, profissão, circunstâncias ou orientação política. (Cohen-Cruz, 2005, p. 2)

Outros autores, apesar de utilizarem outros nomes, também situam estas práticas em comunidades. Helen Nicholson ${ }^{4}$ utiliza o termo Applied Drama (Drama Aplicado), título de seu mais recente livro:

[Teatro Aplicado] é uma investigação sobre o valor e os valores do drama, teatro e a performance que acontecem num local da comunidade e num contexto educacional. É sobre o fazer teatral em diferentes locais, algumas vezes nada glamurosos - como por exemplo, asilos de idosos, abrigos de sem-tetos, escolas e prisões dirigidas por praticantes que têm experiência facilitando drama com participantes community-based (baseados na comunidade). (Nicholson, 2005, p.2)

Um termo semelhante Applied Theatre (Teatro Aplicado) é proposto por Philip Taylor ${ }^{5}$, embora faça referência a um direcionamento mais explícito da prática teatral, voltada para solução de problemas:

Applied Theatre opera a partir de um princípio central de transformação: gerar consciência sobre assuntos particulares (prática sexual segura), ensinar conceitos particulares (alfabetização e matemática), questionar ações humanas (crimes odiondos, relações raciais), prevenir comportamentos perigosos (violência doméstica, suicídio de jovens), para curar identidades rompidas (abuso sexual, imagem corporal), mudar situações de opressão (vitimização pessoal, proibição política de votação). Esses princípios de transformação são próximos de outros movimentos participativos e de teatro comunitário, onde a principal ênfase recai nas aplicações do teatro para ajudar as pessoas a refletir mais criticamente no tipo de sociedade em que desejam viver. (Taylor, 2003, p.1)

Outro termo usado na bibliografia que também se refere a práticas teatrais com comunidades é o popular Theatre (Teatro Popular): 


\section{Urdimento}

Teatropopularéum processo teatralque envolveprofundamente comunidades específicas na identificação dos temas de sua preocupação, analisando as condições existentes e causas de situações, identificando pontos nevrálgicos, e analisando como uma mudança pode acontecer elou contribuindo para a ação implicada. O teatro é sempre parte do processo de identificação e da exploração de como a situação ou o assunto pode ser mudado. (Prentki; Selman, 2000, p. 8)

É interessante notar que, apesar da diversidade de entendimento do significado do trabalho voltado para comunidades e da terminologia usada para designá-lo, existe uma unanimidade no reconhecimento da influência de Paulo Freire e Augusto Boal, presentes na bibliografia pesquisada (Cohen Cruz, 2005, p. 98); (Cohen Cruz, 2005, p. 98); (Prentki; Selman, 2000, p.12).

Enfim, havia uma ampla bibliografia sobre teatro em comunidade que, apesar da diversidade de nomes e de abordagens metodológicas, possuíam pontos em comum com o que eu fazia em Florianópolis.

\section{Teatro e Comunidade no Brasil}

Reconhecer o trabalho em Ratones como Teatro na Comunidade e identificar a vinculação desta prática com trabalhos feitos nos diversos continentes do planeta foram passos que levaram à sedimentação de um campo de pesquisa. Seria o trabalho com a comunidade de Ratones um trabalho isolado? Alguns indicadores me levavam a pensar que sim: a bibliografia sobre teatro em comunidades no Brasil era rara, nas conferências que eu tomava parte, pouco se falava sobre trabalhos nessa área e este conteúdo não fazia parte dos currículos da grande maioria dos cursos de Artes Cênicas. Existiriam outras práticas significativas nessa área, no Brasil?

O projeto de pesquisa "Banco de Dados em teatro para o desenvolvimento de comunidades" foi formulado a partir da necessidade de contribuir para o mapeamento dessa modalidade de práticas de teatro, no Brasil, através do preenchimento de formulário on $\operatorname{line}^{6}$. Partindo de pesquisa de endereços eletrônicos de grupos a serem contatados, identificamos trabalhos diversos e solicitamos que respondessem o questionário e que passassem a fazer parte do Banco de Dados. O formulário foi concretizado, mas seu preenchimento ficou aquém das expectativas. Paralelamente, a pesquisar incluiu investigação sobre grupos específicos, de forma a aprofundar os dados iniciais contidos nos formulários. Nesse trabalho foram identificadas seis modalidades básicas de teatro em comunidades, principalmente relacionadas às instituições a que se vinculam.
${ }^{6} \mathrm{O}$ projeto Banco de dados foi criado em 2005. Pode ser acessado pelo endereço: http://teatrocomunidade.ceart.udesc.br/). 


\section{Urdimento}

7Ver Viganó, Suzana Schmidt As Regras do Jogo: a ação cultural em teatro e o ideal democrático. São Paulo: Hucitec, 2006.

${ }^{8}$ Ver Silva , Rosemeire da; Nogueira, Márcia Pompeo "Estudo de Caso em Teatro na Comunidade: o Grupo União".

${ }^{9}$ As místicas são representações artísticas desenvolvidas coletivamente pelos militantes do Movimento dos Sem Terra há cerca de vinte anos. Segundo João Pedro Stedille, elas têm o objetivo de manter o engajamento e a unidade, dos militantes, na luta pela reforma agrária no Brasil (Stedille, 1999, p.).

${ }^{10}$ Ver Rótulo, Guilherme; Nogueira, Márcia Pompeo "Práticas Teatrais no MST".

\section{"Maria Amélia}

Gimmler Netto pesquisou em 2006 três práticas teatrais comunitárias: Parque dos Maias, Bairro Cristal e Bairro Humaitá, que eram vinculadas aos projetos da Secretaria de Descentralização da Cultura e existiam há mais de três anos. Ver Nogueira, M. P.; Gimmler Netto, M. A "Teatro e Comunidade em Porto Alegre: um estudo de caso".
O Teatro Comunitário religioso é a origem do engajamento de muitos jovens com a prática teatral. Envolve práticas ligadas a datas religiosas como a representação da Paixão de Cristo que pode adquirir contornos mais ou menos comunitários; trabalhos vinculados a grupos de jovens; trabalhos assistenciais etc. A prática teatral com comunidades pode ser identificada junto à religião espírita, pentecostal, católica etc. Destaco, a título de exemplo, o trabalho de conclusão de curso de Reginaldo Maurício Ferreira "O Papel do Teatro Religioso na comunidade do Ribeirão da Ilha: a Encenação da Paixão de Cristo" (2005), que detalha um processo de aprofundamento das qualidades teatrais da encenação da Paixão de Cristo paralelo a um envolvimento crescente da comunidade do Ribeirão da Ilha, Florianópolis, na encenação.

A prática teatral em ONGs tem se multiplicado recentemente. Alguns estudos já se dedicam a esse tema ${ }^{7}$ mas ainda há muito que se aprofundar, em função da quantidade e da variedade de práticas. Vinculada a essa modalidade, a bolsista de iniciação científica Rosimeire da Silva pesquisou a prática do “Grupo Nova União”, coordenado por Virginia Costabile, a partir de contato com a ONG Novo Olhar, que atua em São Miguel Paulista, São Paulo ${ }^{8}$.

A ligação do teatro em comunidades com movimentos sociais pode ser identificada, por exemplo, no trabalho de teatro no MST - Movimento dos Trabalhadores Rurais Sem Terra. Além de uma prática bastante teatralizada, que existe desde a origem do movimento, as chamadas Místicas ${ }^{9}$, o MST recebe influência do Teatro do Oprimido que já ofereceu oficinas para multiplicadores do movimento. Outras influências vêm de contatos de grupos teatrais com o MST, como por exemplo a Companhia do Latão que influenciou o trabalho do grupo do MST Filhos da Mãe... Terra. O bolsista de iniciação científica, vinculado a esse projeto, Guilherme Rótulo, pesquisou a prática teatral no MST, identificando uma rede de trabalhos teatrais comunitários vinculada a esse movimento político $^{10}$. O que impressiona nessa vinculação do teatro em comunidade é a incorporação da estrutura e organização política para disseminar a prática teatral.

A proposta de práticas teatrais comunitárias enquanto políticas públicas acontece diferentemente em cidades brasileiras. A bolsista de iniciação científica Maria Amélia Gimmler $\mathrm{Netto}^{11}$, vinculada a esse projeto, nos aproximou das Oficinas Populares de Teatro, da Secretaria da Descentralização da Cultura em Porto Alegre. Criadas na gestão do Partido dos Trabalhadores na prefeitura desta capital, o trabalho pôde se manter por muitos anos, criando diversos grupos que são articulados em diferentes eventos. Muitos deles atuam em comunidades específicas por vários anos. Três desses grupos foram investigados pela bolsista no artigo "Em Busca de Práticas Teatrais Comunitárias em Porto Alegre”. 


\section{Urdimento}

O teatro de Grupo também está na origem de muitos trabalhos de teatro em comunidades. Essa ligação pode ter sua origem na necessidade de sobrevivência financeira do grupo e dos seus membros, pode também estar ligada aos objetivos intrínsecos do grupo e pode ainda levar em consideração ambos fatores. A interação da Cia do Latão com o MST, citada acima é um exemplo de uma vinculação intrínseca aos objetivos do grupo.

Existem também práticas teatrais comunitárias que se vinculam a comunidades de local, buscando financiamentos diversos, mas existindo independente deles. Destaco o grupo Nós do Morro, da favela do Vidigal, no Rio de Janeiro, pesquisado por Marina Henriques na UNIRIO ${ }^{12}$. Destaco também a pesquisa do bolsista de iniciação científica, vinculado a esse projeto, Mário César Coelho Gomes, que pesquisou o grupo de teatro de São Gonçalo do Bação ${ }^{13}$, Minas Gerais, cujo trabalho contribui há mais de vinte anos para a afirmação da identidade da cultural da cidade.

Mesmo não esgotando todas as possibilidades de teatro em comunidades, e sabendo que essa classificação apresenta modelos de práticas que muitas vezes se interpenetram, identifico essas seis modalidades de teatro vinculado a comunidades como um vasto campo de pesquisa. $\mathrm{O}$ atual mapeamento do Banco de Dados em Teatro em Comunidades representa apenas a ponta de um iceberg. Cada modelo de teatro em comunidade precisa ser investigado mais amplamente para que sua compreensão possa ser aprofundada.

\section{Referências Bibliográficas}

BAUMAN, Zygmunt. Comunidade: a busca por segurança no mundo atual. Rio de Janeiro: Zahar, 2003.

COELHO, Mario César; Nogueira, Márcia P..” Garimpando o Teatro de São Gonçalo do Bação”. In Anais da IV Jornada de Pesquisa do CEART, 2008 (no prelo).

COHEN, Anthony P. The Symbolic Construction of Community. Londres: Routledge, 1998.

COHEN-CRUZ, Jan. Local Acts: community-based performance in the United States. New Jersey: Rutgers University Press, 2005.

COUTINHO, Marina Henriques; NOGUEIRA, Márcia Pompeo. "The use of dialectical approach for community theatre by the group Nós do Morro, in the Vidigal favela of Rio de Janeiro". In PRESTON, Sheila; PRENTKI, Tim. $A$ Companion to Applied Theatre. Londres: Routledge, 2008.

FERREIRA, Reginaldo Maurício. "O Papel do Teatro Religioso na comunidade do Ribeirão da Ilha: a Encenação da Paixão de Cristo”. Trabalho de Conclusão de Curso, CEART/UDESC, 2005, não publicado. 
GIMMLER Netto, M.A.; NOGUEIRA, M. P, M. A “Teatro e Comunidade em Porto Alegre: um estudo de caso”. In Anais da II Jornada de pesquisa do CEART e 160 Seminário de Iniciação Científica UDESC, 2006

KERSHAW, Baz. The Politics of Performance: Radical Theatre as Social Intervention. Londes: Routledge, 1992.

NICHOLSON, Hellen. Applied Drama: the Gift of Theatre. Basingstoke: Palgrave Macmillan, 2005.

PRENTKI, Tim. Popular Theatre in Political Culture: Britain and Canada in Focus. Bristol: Intellect, 2000.

RÓTULO, Guilherme; NOGUEIRA, Márcia Pompeo "Práticas Teatrais no MST”. In Anais da III Jornada de Pesquisa do CEART, 2007.

SILVA, Rosemeire da; NOGUEIRA, Márcia Pompeo "Estudo de Caso em Teatro na Comunidade: o Grupo União".In Anais da II Jornada de pesquisa do CEART e 160 Seminário de Iniciação Científica UDESC, 2006.

TAYLOR, Philip. Applied Theatre: Creating Transformative Encounters in the Community. Portsmouth: Heineman, 2003.

VIGANÓ, Suzana Schmidt. As Regras do Jogo: a ação cultural em teatro e o ideal democrático. São Paulo: Hucitec, 2006. 